\section{Folia Phoniatrica et Logopaedica}

Assaiante, C. 195

Charman, T. 166

Duez, D. 185

Echternach, M. 278

Espesser, R. 185

Ghio, A. 185, 195

Giovanni, A. 195

Graessel, E. 303

Green, J.R. 297

Hummel, C. 303

Jiang, J.J. 288

Kent, J.F. 297

Kent, R.D. 297

Issues No. 1-2, 3 and 5 have their own Author and Subject Indexes.

Lagier, A. 195

Legou, T. 195

MacCallum, J.K. 288

Markl, M. 278

Nakashima, T. 178,263

Nguyen, N. 185

Nip, I.S.B. 297

Richter, B. 278

Rosanowski, F. 303

Rothwell, J.C. 153

Sato, K. 178, 263

Scharf, M. 303

Schuetzenberger, A. 303
Schutte, H.K. 308

Sundberg, J. 278

Threats, T.T. 158

Umeno, H. 178, 263

Vaugoyeau, M. 195

Wang, Y.-T. 297

Witt, R.E. 288

Woisard-Bassols, V. 185

Wójcicka, G. 271

Wójcicki, P. 271

Zhu, Y. 288

\title{
Subject Index Vol. 62, 2010
}

Aging 178

Articulation 278

Ataxic dysarthria 185

Audio compression 288

Autism 166

- spectrum disorder 166

Breath group 297

Cleft palate 271

Communication disorders 158

Compressed speech 185

Cultural diversity 158

Diagnosis 166

Dysphonia 303

Extracellular matrix 178, 263

Furlow operation 271
Growth and development 263

Handicap, self-perceived 303

Human vocal fold 178, 263

Intelligibility 185

Intervention 166

Jitter 288

Larynx 178, 263

Macula flava 178, 263

Magnetic resonance imaging 278

Motor system, human 153

Objective voice parameters 303

Orticochea operation 271

Phonation 195

Plasticity 153

Posture 195
Reading 297

Register 278

Screening 166

Shimmer 288

Speech disorders 185

- modification 185

Spontaneous speech 297

Transcranial direct current stimulation 153

- magnetic stimulation 153

Velopharyngeal insufficiency 271

Vocal effort 195

- fold stellate cell 178, 263

Voice 278

- over Internet Protocol 288

(c) 2010 S. Karger AG, Basel 